\title{
Role of Intravenous Paracetamol as Pre-Emptive Analgesic for Laparoscopic Cholecystectomy
}

\author{
*S Reza ${ }^{1}$, I Khalilullah ${ }^{2}$, T Habib ${ }^{3}$, JH Chowdhury ${ }^{4}$, T Hasan $^{5}$,

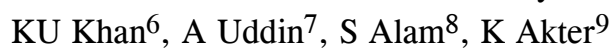

\begin{abstract}
Background: Despite the high level of awareness about the importance of post-operative pain management, lot of investigations and study results show an unacceptable high rate of incidence of pain after surgery. Preemptive pain control is regional or systemic analgesics, applied before starting the surgical procedure. The effect is achieved by suppressing, central or peripheral nociceptors, either together or separately by sensitization. We studied the effect of intravenous Paracetamol as pre-emptive analgesic in patients undergoing laparoscopic cholecystectomy.
\end{abstract}

Method: A total number of 60 adult patient with ASA physical status I \& II scheduled for Laparoscopic cholecystectomy under general anaesthesia were randomly enrolled in this study. Patients were randomly allocacated equally into two groups $\mathrm{A}$ and $\mathrm{B}$ according to computerized random table, 30 in each group. Patients of Group A $(\mathrm{n}=30)$ received I.V Paracetamol $10 \mathrm{mg} / \mathrm{kg}(100 \mathrm{ml}) 10$ min before skin incision and Group B $(\mathrm{n}=30)$ received $100 \mathrm{ml}$ of Normal saline $10 \mathrm{~min}$ before skin incision. It was a single blind, randomized, prospective, case-control study. Observation and management of pain, nausea, vomiting, respiratory depression, allergic reaction, amount of opioid requirement and time of analgesic demand after operation were carried out in data collection sheet.

Result: The total dose of postoperative opioid needed in Group-A was significantly lower than that in the Group$\mathrm{B}(\mathrm{p}=0.012)$. The pain scores were comparatively low in case of group-A than that in Group-B from beginning to 24 hours of evaluation following operation $(\mathrm{p}=0.027)$. About one-third $(32 \%)$ of the patient in each group experienced nausea at 1 hour interval post operatively. However, the complaint of nausea at 6 and 12 hours was much less in the Group-A than that in the Group-B. Vomiting was negligible in either group. Majority (80\%) of patient in Group-B demanded analgesic (pethedine) 10 minutes earlier after operation as opposed to only $8 \%$ of patients in Group-A ( $<0.001)$. No other side effects were recorded in either of the groups.

Conclusion: Our findings indicate that pre-emptive administration of iv Paracetamol $(10 \mathrm{mg} / \mathrm{kg})$ in patients undergoing Laparoscopic Cholecystectomy ensures an effective postoperative analgesia, increases the time to first analgesic requirement and reduces opioid consumption.

Key Words: Pre-emptive analgesia, Intravenous Paracetamol, Laparoscopic cholecystectomy.

$1 * D r$. Sultan Reza, Associate consultant, Neuro ICU, Square Hospitals Ltd. Phone: 01732255678

e-mail: sultanrezamanha@gmail.com

${ }^{2}$ Dr. Ibrahim Khalilullah, Registrar \& Specialist, Dept. of Anesthesiology, Ibrahim Cardiac Hospital \& Research Institute

${ }^{3}$ Dr. Tamanna Habib, Assistant Professor, Dept. of Physiology, Anwer Khan Modern Medical College

${ }^{4}$ Dr. Jayed Hossain Chowdhury, Associate Consultant, Dept. of Anesthesiology, Square Hospitals Ltd

${ }^{5}$ Dr. Tarikul Hasan, Associate Consultant, Dept. of Anesthesiology, Square Hospitals Ltd

${ }^{6}$ Dr. Kutub Uddin Khan, Consultant, Dept. of Anesthesiology, Imperial Hospital

${ }^{7}$ Dr. Aftab Uddin, Consultant, Anesthesiology, Sheikh Fazilatunnessa Mujib Memorial KPJ Specialized Hospital \& Nursing College, Gajipur

${ }^{8}$ Dr. Shafiul Alam, Assistant Professor, Anesthesiology, BIRDEM Hospital

${ }^{9}$ Dr. Khaleda Akter, Specialist, Laboratory, Ibrahim Cardiac Hospital \& Research Institute

*Corresponding Author

Date of submission: 23.04.2019 Date of acceptance: 10.06.2019

AKMMC J 2019; 10(2) : 159-163 


\section{Introduction}

Pain is an unpleasant sensory and emotional experience associated with actual or potential tissue damage or described in terms of such damage. ${ }^{1}$ Postoperative pain is a common problem with serious implications in terms of patient outcomes and health care costs. Pre-emptive pain control is that, regional or systemic analgesics applied before starting the surgical procedure. The importance of peripheral and central modulation in nociception has forced the concept of pre-emptive analgesia in patients undergoing surgery. This type of management pharmacologically induces an effective analgesic state prior to surgical trauma. Pre-emptive analgesia can effectively attenuate peripheral and central sensitization to pain. ${ }^{2,3}$ Pre-emptive analgesia can be directed at central neurons by using NSAID, Paracetamol, Ketamine, local anaesthetics and opioids either alone or in combination. Although laparoscopic cholecystectomy is less invasive procedure than classical open surgical approach, many laparoscopic patients suffer considerable post operative pain. One of the main causes of the pain after laparoscopic cholecystectomy is the peritoneal irritation caused by the pneumo peritonium. Opioid commonly used in post operative period has considerable side effect like nausea and vomiting. ${ }^{4,5}$ Pre-emptive analgesia with I.V Paracetamol reduces the opioid requirement, thus reducing the nausea and vomiting. Paracetamol inhibits the release of prostaglandin in the spinal cord, also has effect on serotonin mechanism for spinal pain inhibation. It also reduced nitric oxide production in CNS. 6,7

\section{Materials \& Methods}

This was a prospective, randomized, single-blinded case-control study on intravenous Paracetamol as pre-emptive analgesic. It was carried out in the department of Anaesthesiology, Square Hospitals Ltd, Dhaka, during the period of July 2014 to December 2014. Ethical clearance was taken from the Institutional ethical body. Patients scheduled for laparoscopic cholecystectomy under general anaesthesia were enrolled in this study. A total of 60 patients were randomly included in the study out of
100 selected patients. Patients were randomly allocated equally into two groups A and B according to computerized table, 30 in each. Patients of Group A $(n=30)$ received I.V Paracetamol $10 \mathrm{mg} / \mathrm{kg}$ $(100 \mathrm{ml})$ and Group B $(n=30)$ received $100 \mathrm{ml}$ of Normal saline 10 min before skin incision. Inclusion Criterias were all surgical patients for laparoscopic cholecystectomy of both sexes who were mentally sound and able to understand the procedure. Age between 16-60 years, ASA grading I, II. Exclusion criterias were patients unable to understand normal command/suggestion, patient refusal, known allergy to Acetaminophen, hypertensive patient, diabetic patient, patients with renal impairment and Chronic Obstructive airway disease. Main outcome variables were Post Anaesthetic Heart Rate, Blood Pressure, Respiratory rate, VAS (Visual Analogue Scale), $\mathrm{SpO}_{2}$, First analgesic (Pethidine) requirement, Total analgesic requirement, allergic reaction, stomach irritation at $1 \mathrm{hr}, 2 \mathrm{hr}, 4 \mathrm{hr}, 8 \mathrm{hr} 12 \mathrm{hr} \& 24 \mathrm{hr}$.

\section{Data Analysis}

Data were processed and analysed using SPSS (Statistical Package for social sciences) windows version 17. For all analytic tests, the level of significance was set at 0.05 and $\mathrm{p}<0.05$ was considered significant. The summarized data were presented in the form tables and charts.

\section{Result}

Both groups were comparable with regard to demographic variables (age, gender and weight), ASA physical status and the mean duration of surgery time. Mean age of the Group-A was somewhat lower than that of the Group-B $(39.3 \pm 4.3$ years and $37.4 \pm 4.4$ years respectively) $(\mathrm{p}=0.133)$. Female patients were predominant in the both Group-A (64\%) and the Group-B (68\%) groups. Mean body mass index was almost similar between groups $\left(23.8 \pm 1.4\right.$ vs $23.7 \pm 0.8 \mathrm{~kg} / \mathrm{m}^{2}$, $\mathrm{p}=0.908$ ). Mean operation time was higher in the Group-B compared to the Group-A, although the difference between the groups did not turn to significant $(61.7 \pm 8.8$ vs $56.5 \pm 9.4$ minutes, $\mathrm{p}=0.066$ ). Demographic data \& duration of surgery. 
Table 1: The demographic variables \& operation durations are showing

\begin{tabular}{lccc}
\hline & Group - A & Group - B & p value \\
\hline Age (years) & $39.3 \pm 4.3$ & $37.4 \pm 4.4$ & 0.133 \\
Sex & Male: $36 \%$ & Male: $32 \%$ & \\
BMI $\left(\mathrm{kg} / \mathrm{m}^{2}\right)$ & $23.8 \pm 1.4$ & $23.7 \pm 0.8$ & 0.908 \\
$\begin{array}{l}\text { Duration of surgery } \\
\text { (minutes) }\end{array}$ & $61.7 \pm 8.8$ & $56.5 \pm 9.4$ & 0.066 \\
\hline
\end{tabular}

Student's $t$ Test was employed to analyze the data and the data presented as mean $\pm S D$.

The mean pain score at 1 hour after operation was $4.4 \pm 0.3$ in Group-A and $4.7 \pm 0.3$ in Group-B which decreased to $2.7 \pm 0.3$ and $2.9 \pm 0.2$ respectively at 6 hours, $1.7 \pm 0.2$ and $1.8 \pm 0.2$ respectively at 12 hours and $1.0 \pm 0.1$ and $1.1 \pm 0.2$ respectively at 24 hours interval. The pain scores were comparatively low in Group-A than that in the Group-B from beginning to end point of evaluation following operation $(\mathrm{p}=0.027)$ (Table 2). The mean amount of pethidine required at 1 hour was $34.8 \pm 5.4 \mathrm{mg}$ and $36.6 \pm 5.0 \mathrm{mg}$ in Group-A and Group-B respectively which increased abruptly at 6 hours to $77.3 \pm 10.7$ and $92.1 \pm 8.5 \mathrm{mg}$ respectively. Then the amount decreased steeply at 12 hours to $29.4 \pm 5.4$ and $28.1 \pm 4.7 \mathrm{mg}$ respectively. The total amount of pethidine needed was significantly lower in the Group-A than that in the Group-B $(126.8 \pm 14.4$ vs. $139.6 \pm 9.5 \mathrm{mg}$ respectively, $\mathrm{p}=0.012$ ) (Table 2 ).

Table 2: Comparison of pain score, Required pethidine dose and First analgesic demand after surgery between two groups

\begin{tabular}{lccc}
\hline Pain score & \multicolumn{2}{c}{ Group } & \multirow{2}{*}{ - value } \\
\cline { 2 - 3 } & Group- B(n=30) & Group- A(n=30) & \\
\hline Pain score at 1 hr & $4.7 \pm 0.3$ & $4.4 \pm 0.3$ & \\
Pain score at 6 hr & $2.9 \pm 0.2$ & $2.7 \pm 0.3$ & 0.027 \\
Pain score at 12hr & $1.8 \pm 0.2$ & $1.7 \pm 0.2$ & \\
Required pethidine (mg) & & \\
at 1 hr & $36.6 \pm 5.0$ & $34.8 \pm 5.4$ & \\
at $6 \mathrm{hr}$ & $92.1 \pm 8.5$ & $77.3 \pm 10.7$ & $<0.001$ \\
at $12 \mathrm{hr}$ & $28.1 \pm 4.7$ & $29.4 \pm 5.4$ & \\
Total amount needed & $139.6 \pm 9.5$ & $126.8 \pm 14.4$ & 0.012 \\
First analgesic demand (minutes after surgery) & \\
$<10$ & $2(8.0)$ & $2(8.0)$ & \\
$10-20$ & $6(20.0)$ & $12(40)$ & $<0.001$ \\
$>20$ & 00 & $16(52)$ & \\
\hline
\end{tabular}

Repetitive measure Paired t-test was used to analyse the data for pain score, Data of Required pethidine dose were analysed using Student's $t$ - test and Data of first analgesic demand after surgery were analysed using $\chi^{2}$ test \& figures in the parenthesis denoted corresponding percentage. All data were presented as mean $\pm S D$.

Half $(52 \%)$ of patients in the Group-A demanded analgesic (pethidine) between $\geqslant 20$ minutes after operation, $40 \%$ between $10-20$ minutes and the rest $8 \%$ before 10 minutes. While, majority $(80 \%)$ of patients in the Group-B demanded analgesic before 10 minutes and rest $20 \%$ between 10-20 minutes. Early demand of analgesic in $<10$ minutes after operation was subsequently lower in the Group-A than that in the Group- B $(\mathrm{p}<0.001)$ (Table 2).

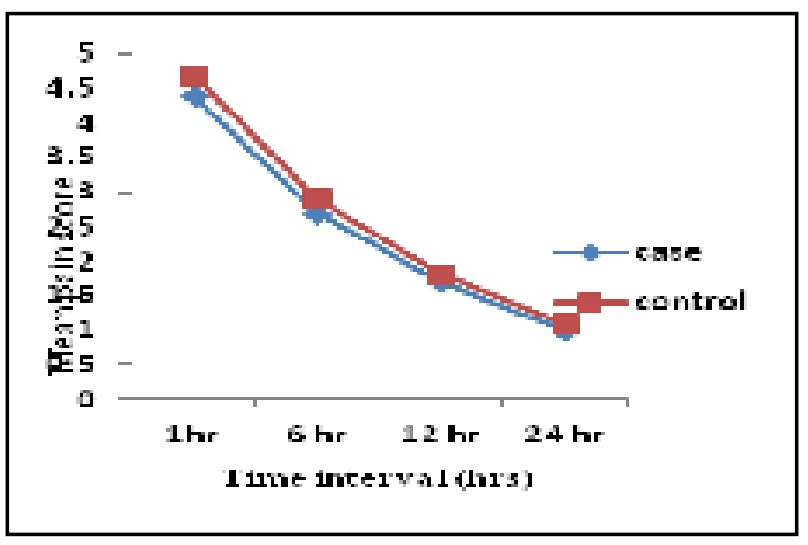

Figure 1: Pain score at different time interval between groups

\section{Postoperative Complications}

Table 3 depicts that about one third (32\%) of the patients in each group experienced nausea at 1 hour interval postoperatively. However, the complaint of nausea at 6 hours of observation was much less in the Group-A than that in the Group-B. Vomiting was negligible in either case.

Table 3: Comparison of post operative complication between groups

\begin{tabular}{lccc}
\hline Complication & \multicolumn{2}{c}{ Group } & p- value \\
\cline { 2 - 3 } & Group- B(n=30) & Group- A(n=30) & \\
\hline Nausea & $10(40.0)$ & $10(40.0)$ & \\
At 1 hour* & $16(64.0)$ & $12(48.0)$ & $<0.001$ \\
At 6 hour* & $4(16.0)$ & $3(12.0)$ & \\
At 12 hour $\#$ & & & \\
Vomiting & & & \\
At 6 hour & $1(4.0)$ & $0 \mathrm{z}$ & 0.500 \\
At 12 hour & 00 & $5(20.0)$ & 0.117 \\
\hline
\end{tabular}

Data were analysed using $\chi^{2}$ test.\#fisher's exact test was done to analyze the data. 


\section{Discussion}

Preemptive analgesia means that an analgesic intervention is started before the noxious stimulus arises in order to block peripheral and central nociception. ${ }^{8}$ NSAIDs when given before tissue damage (preemptive) may play an important role in per-operative pain management by reducing the inflammatory response in the periphery and thereby decreasing sensitization of peripheral nociceptors. Many trials have been able to demonstrate preemptive effect of NSAIDs on the reduction of postoperative pain in laparoscopic cholecystectomy. ${ }^{9}$

Various studies were carried out to show the effect of I.V paracetamol as a pre-emptive analgesic, also the requirement of opioid in post-operative period. The idea was to keep the Heart rate and B.P changes minimum and prevent the post-operative complication (eg.nausea, vomiting etc.). ${ }^{10}$ The results of controlled clinical studies demonstrated that the recommended therapeutic doses of intravenous paracetamol is safe and well tolerated, with a profile that supports the high reliability similar to placebo. Paracetamol is considered to be a safe drug and it has no gastrointestinal and central nervous system side effects like opioids and NSAID. ${ }^{11,11 . a}$

Paracetamol intravenous $1 \mathrm{~g}$ has analgesic activity in moderate to severe post-operative pain similar those have shown ketorolac $30 \mathrm{mg}^{12}$, diclofenac $75 \mathrm{mg}^{13}$, morphine $10 \mathrm{mg}^{14}$ In a double-blind placebocontrolled study, it has been shown that using the combination of intravenous paracetamol and ketopropefen reduce post-operative pain and cumulative opioid consumption in the first $48 \mathrm{~h}$ following surgery. ${ }^{15}$ It also demonstrated that intravenous paracetamol has the effect on reducing the use of opioid. It reduces the need for the patient's total opioid by the rate of $24-46 \%$ and increases in patient's satisfaction.

In a study conducted in 2010 by Memis and colleagues, they reviewed the effect of intravenous Paracetamol. They concluded that intravenous Paracetamol reduces opioid consumption, the extubation time, and opioid side effects, such as nausea, vomiting, and itching. ${ }^{16}$ In this study, the same as our study, Paracetamol used for postoperative pain control had significant difference in the pain control between the groups, but unlike our study was also effective in reducing opioid consumption. In another study by Brodner and colleagues on patients undergoing mild to moderate surgery with general anesthesia, it was concluded that Paracetamol and other non opioid analgesics have a similar effect. ${ }^{17}$ Postoperative pain was reduced with non-narcotic medication in comparison to placebo with no effect on pain control. Furthermore, in our study, the effect of Paracetamol was significant in the pain control. Another study conducted by Samson and colleagues in 2009 to see the efficacy and pharmacokinetics of intravenous Paracetamol on ICU patients. They found that after administration of $1 \mathrm{gm}$ intravenous Paracetamol four times a day, the optimal therapeutic dose is not available. ${ }^{18}$

Fijalkowska et al. ${ }^{19}$ investigated the effectiveness of iv Paracetamol to 92 patients scheduled for laparotomy or laparoscopy. In laparoscopy group, $16.3 \%$ of patients needed additional morphine, while in the laparotomy group, $71.4 \%$ patients had additional morphine requirement. They concluded that paracetamol reduces the need for opioid analgesics but in major surgeries a multimodal approach must be needed.

In our study in group B, we identified additional analgesic required in $66 \%$ of patients while in group Additional analgesic required in $43 \%$ of patients. The time first analgesic requirement was longer in group A than in group $\mathrm{B}$ which was statistically significant $(\mathrm{P}=$ 0.0329). We found that the use of preemptive iv Paracetamol reduce opioid requirements, prolong the duration to first need of analgesia and provide a significant reduction in post-operative pain scores. The reduction in total opioid consumption may also be due to the opioid sparing effect of pre-emptive Paracetamol which has been seen in other studies as well. ${ }^{20,11}$

The reduction of this dose during the first days of treatment is an important factor in improving tolerability. The most common adverse effects of opioid are nausea, vomiting, respiratory depression, dizziness, fatigue, sweating, dry mouth, drowsiness and orthostatic hypotension. ${ }^{22}$ In our patients, only nausea and vomiting were observed. The incidence of side effects was equal in both the groups. 


\section{Conclusion}

This study demonstrated that the early postoperative analgesic effect of Paracetamol $(10 \mathrm{mg} / \mathrm{kg})$ in patients undergoing laparoscopic cholecystectomy. It reduced opioid consumption with lower side effects, Paracetamol can be safely used in postoperative pain management.

Conflict of interest: None.

\section{Reference}

1. Morgan GE, Mikhall MS \&amp; Murray MJ, Clinical anaesthesiology, Lange Medical Books/McGraw-Hill, 2006; 361.

2. Dhal JB, Moiniche S. Pre-emptive analgesia. British Medical Bulletin. 2004; 71(1): 13-25.

3. Bonnefont J, Courade JP, Alloui A, et al. Antinociceptive Mechanism of action of paracetamol. Drugs . 2003; 63: 1-4.

4. Arslan M, Çiçek R, Celep B, et al. Comparison of the analgesic effects of intravenous paracetamol and lornoxicam in postoperative pain following thyroidectomies. Agri 2011; 23: 160-166.

5. Rumack BH. Acetaminophen hepatotoxicity; the first 35 years. Clinical toxicology. 2002; 40(1): 3-20.

6. Kissin I. Pre-emptive analgesia. Anaesthesiology 2000; 93: 1138-1143.

7. Arslan M, Celep B, Cicek R, et al. "Comparing the efficacy of pre-emptive intravenous paracetamol on the reducing effect of opioid usage in cholecystectomy." Journal of Research in Medical Sciences. 2013; 18(3): 172-177.

8. Grape S, Tramer MR. Do we need preemptive analgesia for the treatment of post operative pain. Best pract Res Clin anathesiol. 2007; 21(1): 51-63.

9. Dhal JB, Moiniche S. Preemptive analgesia. British Medical Bulletin. 2004; 71: 13-27.

10. Charlton JE. Treatment of post operative pain. Giamberardino MA, editor review: refresher course syllabus. Seattle: IASP Press; 2002. 351-355.

11. Arslan M, Çiçek R, Celep B, et al. Comparison of the analgesic effects of intravenous paracetamol and lornoxicam in postoperative pain following thyroidectomies. Agri 2011; 23: 166-168.

11a. Prescott LF. Pharmacological actions and therapeutic use of paracetamol. In: Paracetamol (Acetaminophen): A Critical Bibliographic Review. London: Taylor and Francis.1996; 197- 539.
12. Lee SY, Lee WH, Lee EH, et al. The effects of paracetamol, ketorolac, and paracetamol plus morphine on paincontrol after thyroidectomy. Korean J Pain. 2010; 23: 124-30.

13. Akarsu S, Sahin S, Kara C, et al. A comparison between parenteral paracetamol and diclofenac for acute postoperetive pain treatment in patients after caeserean section. JTurk Soc Obstet Gynecol. 2010; 7: 262-266.

14. Craig M, Jevons R, Probert J, et al. Randomised comparison of intravenous paracetamol and intravenous morphine for acute traumaticlimb pain in the emergency department. Emerg Med J. 2012; 29: 37-39.

15. P. E. Macintyre Safety and efficacy of patient? controlled analgesia. Br J Anaesth. 2001; 87: 36-46.

16. Memis D, Inal MT, Kavalci G, et al. Intravenous paracetamol reduced the use of opioids, extubation time and opioid-related adverse effect after major surgery in intensive care unit. J critical care. 2010; 25(3): 458-462.

17. Brodner G, Gogarten W, Van Aken H, et al. Efficacy of intravenous paracetamol compared to dipyrone and parecoxib for postoperative pain management after minor-to-intermediate surgery. European J Anaesthesiol. 2011; 28(2): 125-132.

18. Samson AD, Hunfeld NG, Touw DJ, et al. Efficacy and pharmacokinetics of intravenous paracetamol in the critical ill patient.29th international symposium on intensive care and emergency medicine. Critical Care. 2009; 13: 407.

19. Fijalkowska A, Trela-Stachurska K, Rechberger T. Efficacy of i.v paracetamol for early postoperative analgesia after gynaecological surgery. Anaesth Int Therapy. 2006; 38: 60-63.

20. Arici S, Gurbet A, Türker G, et al. Pre-emptive analgesic effects of intravenous paracetamol in total abdominal hysterectomy. Agri. 2009 Apr; 21(2): 54-61.

21. Leppert W. Tramadol as an analgesic for mild to moderate cancer pain. Pharmacol Rep. 2009; 61(6): 978-992.

22. Güner $\mathrm{AD}$, Baydar $\mathrm{M}$, Gökçmnar $\mathrm{D}$, et al. $\mathrm{A}$ comparison between paracetamol and tramadol for postoperative pain treatment in patients undergoing midline abdominal incision. New J Med. 2007; 24: 160-163. 